\title{
ANÁLISE DA ATUAÇÃO DO TRIBUNAL DE CONTAS DO RIO DE JANEIRO ANTES E APÓS A OPERAÇÃO QUINTO DO OURO
}

\author{
Daniel Kowarski* \\ Marcelo Ludolf**
}

Resumo: O trabalho visa analisar o impacto das mudanças ocorridas em decorrência de abrupta alteração da composição do Tribunal de Contas do Estado do Rio de Janeiro (TCERJ) ocorrida em 2017, na qual cinco conselheiros efetivos, concomitantemente, foram afastados por determinação judicial. Os referidos membros efetivos, nomeados através de processo de escolha impregnado de viés político, foram substituídos por auditores públicos originários de concurso público. A pesquisa visa comparar determinados dados empíricos extraídos de relatórios públicos de atividades sobre produtividade, efetividade e estrutura do controle do TCE-RJ, por meio de um recorte de período anterior e outro posterior à mudança, com o objetivo de apresentar possíveis tendências. Pretende-se observar se houve alteração na orientação do TCE-RJ, o qual passou a ser formado exclusivamente por julgadores concursados, seja sob o viés mais ou menos intervencionista e fiscalizador, seja sob a dimensão da produtividade. Concluindo ao final se é possível deduzir que um Tribunal de Contas, formado por indicados políticos, possui maior inclinação de representar possível captura política.

Palavras-Chave: Fiscalização. Tribunal de Contas. Tribunal de Contas do Estado do Rio de Janeiro. Análise descritiva.

\section{ANALYSIS OF THE PERFORMANCE OF THE COURT OF AUDIT OF RIO DE JANEIRO BEFORE AND AFTER THE QUINTO DO OURO OPERATION}

\begin{abstract}
The article aims to analyze the impact of the changes that occurred as a result of the abrupt change in the composition of the Court of Accounts of the State of Rio de Janeiro (TCE-RJ) that occurred in 2017, in which five effective Councilors, at the same time, were dismissed by judicial order. The effective councilors were appointed through a selection process steeped in political bias, having then been replaced by tendered councilors. The descriptive work compared the productivity of the TCE three years before and three years after the change between the two forms of composition, in order to present trends based on empirical data. Concluding at the end if it is possible to deduce that a Court formed by nominees has a greater chance of representing possible political capture.
\end{abstract}

Keywords: Inspection. Audit Office. Court of Auditors of the State of Rio de Janeiro. Descriptive analysis.

\footnotetext{
* Mestrando em Direito da Regulação pela Escola de Direito do Rio de Janeiro da Fundação Getúlio Vargas FGV Direito Rio. Especializado em Direito Empresarial pela Fundação Getúlio Vargas - FGV. Graduado pela Pontifícia Universidade Católica do Rio de Janeiro. Advogado. dkowarski@ cedae.com.br

** Mestrando em Direito da Regulação pela Escola de Direito do Rio de Janeiro da Fundação Getúlio Vargas FGV Direito Rio. Especializado em Direito Tributário pelo Instituto Brasileiro de Estudos Tributários. Graduado pela Pontifícia Universidade Católica do Rio de Janeiro. Advogado. Email. mludolf@basilioadvogados.com.br.
} 


\section{Introdução.}

Questão que pulula os debates políticos e jurídicos no País diz respeito à forma de nomeação dos ministros do TCU e conselheiros dos Tribunais de Contas Estaduais (TCEs). Por previsão Constitucional, dois terços dos ministros do Tribunal de Contas da União (TCU) e dos conselheiros dos TCEs são escolhidos pelo Legislativo. Essa arquitetura de escolha difere dos Tribunais Superiores integrantes do Poder Judiciário.

Tal abertura política na escolha dos respectivos ministros e conselheiros traz um debate sobre a possibilidade de captura política do controle externo ${ }^{1}$, tanto que existem diversas propostas de emenda à Constituição Federal com o objetivo de alterar a forma de ingresso dos ministros do TCU e dos conselheiros dos TCEs, com o objetivo de evitar uma possível captura política ${ }^{2}$. Como forma de exercer o controle dos TCs, existe também

\footnotetext{
${ }^{1}$ Willeman ressalta que "esse modelo de definição do corpo deliberativo dos Tribunais de Contas não tem se revelado capaz de evitar a captura política e práticas clientelistas em tais órgãos, colocando em xeque a própria credibilidade do sistema de controle" (WILLEMAN, 2020, p. 33). Já Luciano Vieira, ao avaliar as escolhas dos conselheiros dos Tribunais de Contas estaduais, sugere que, apesar dos requisitos legais de idoneidade moral e reputação ilibada, estes seriam sistematicamente vilipendiados, por meio de um odioso fisiologismo e corporativismo, no qual o Executivo e Legislativo preencheriam tais cargos "por apadrinhados políticos, geralmente ocupantes de cargos de secretariado, e por deputados - apesar de a muitos deles faltar o indispensável conhecimento técnico ou atributos de ordem moral" (VIEIRA, 2020). Ademais, salienta que os conselheiros dos TCs "por vezes funcionam como fiéis garantidores do cumprimento de dívidas eleitorais" e, por isso, "deputados e governador não se intimidam em indicar para o cargo pessoas dispostas a alimentar o fisiologismo à custa de recursos compulsoriamente obtidos dos cidadãos" (VIEIRA, 2020). De acordo com Rodrigo Monteiro Da Silva, "estudos realizados pela Associação Nacional do Ministério Público de Contas mostra que quarenta e oito dos duzentos e quarenta Ministros e Conselheiros de Tribunais de Contas sofreram (ou sofrem) algum tipo de investigação relacionada a atos de corrupção. Há, assim, a constatação de que vinte por cento dos integrantes das Cortes de Contas brasileiras, em tese, não possuem idoneidade moral e reputação ilibada para o exercício da função" (DA SILVA, 2018).

${ }^{2}$ Encontram-se em trâmite no Congresso Nacional as seguintes propostas de emenda à Constituição que visam alterar a forma de nomeação dos Ministros do TCU: PEC 123/1999, a qual dispõe que os Ministros do Tribunal de Contas da União serão escolhidos mediante realização de concurso público de provas e títulos; PEC $\mathrm{n}^{\circ}$ 209/2003, que altera o caput e o parágrafo único do art. 75 da Constituição Federal, para determinar que os Conselheiros dos Tribunais de Contas dos Estados, do Distrito Federal e dos Conselhos de Contas dos Municípios sejam escolhidos por meio de concurso público; PEC nº 222/2003, a qual dispõe que os Ministros membros do TCU denominar-se-ão "Ministros-Auditores" e serão escolhidos mediante concurso público; PEC 427/2005, que dispõe sobre a aplicação de concurso público para escolha de 3 (três) Ministros do TCU; PEC 316/2008, que retira do Executivo Federal a faculdade de escolher alguns membros do TCU, e estabelecendo que cinco desses membros serão escolhidos, pelo Congresso Nacional, dentre os indicados em listas encaminhadas pelos Conselhos de Contabilidade, Economia e Administração e da OAB; PEC 587/2002. Consta ainda em trâmite no Congresso Nacional a PEC $n^{\circ} 329 / 2013$, a qual altera a forma de composição dos Tribunais de Contas; submete os membros do Ministério Público de Contas ao Conselho Nacional do Ministério Público CNMP e os Conselheiros e Ministros dos Tribunais de Contas ao Conselho Nacional de Justiça - CNJ e dá outras providências. E por fim, a mais recente PEC n ${ }^{\circ} 2 / 18$ do Senado Federal, na qual visa eliminar o critério da indicação política para impor ao TCs uma composição majoritária de selecionados em concursos públicos de provas e títulos, invertendo a forma atual de escolha.
} 
proposta de emenda à Constituição Federal, cujo objetivo é a criação do Conselho Nacional dos Tribunais de Contas $^{3}$.

Assim, é conveniente aprofundar o estudo sobre o modo de escolha desses "magistrados financeiros", os quais exercem a relevantíssima função de fiscalizar a Administração Pública sob diversos enfoques, evitando que os debates sobre a forma de composição dos TCs sejam realizados exclusivamente através de aspectos ideológicos desprovidos de dados. A princípio, existe uma dificuldade para avaliar empiricamente os diferentes modelos de composição dos TCs, uma vez que, em regra, seus membros são majoritariamente oriundos do meio político.

Ocorre que, no dia 29 de março de 2017, o Tribunal de Constas do Estado do Rio de Janeiro (TCE-RJ) sofreu sua mais abrupta mudança de estrutura e composição, decorrente do afastamento simultâneo, por determinação judicial, de cinco efetivos conselheiros. Tratou-se da Operação Quinto do Ouro ${ }^{4}$, deflagrada pela Polícia Federal, tendo como base a delação premiada do ex-presidente do TCE-RJ, Jonas Lopes de Carvalho Junior. Após o recebimento da denúncia, os cinco conselheiros se tornaram réus pelos crimes de corrupção passiva e lavagem de dinheiro e permanecem afastados de suas atividades desde então. Com a prisão e o afastamento de cinco conselheiros do TCE-RJ (superior a $70 \%$ da composição), todos oriundos de escolha política, houve uma radical mudança na composição da Corte, uma vez que os novos integrantes passaram a ser os auditores públicos do Tribunal (LIMA, 2015), aprovados mediante concurso público. A única remanescente da antiga composição é a conselheira Mariana Montebello Willeman, ex-integrante do Ministério Público do TCE-RJ, cujo ingresso também se deu mediante aprovação em concurso público.

Então, após a Operação Quinto do Ouro, o TCE-RJ tornou-se um "laboratório" para avaliar quais são as possíveis mudanças que podem ser observadas no exercício do controle

\footnotetext{
3 A PEC 22/2017 propõe a criação do Conselho Nacional dos Tribunais de Contas (CNTC), enquanto instrumento de aprimoramento da função constitucional desses órgãos, assim como pela modificação na sua forma de composição, com incremento do rigor e do detalhamento dos critérios e dos requisitos para a investidura dos seus membros; inclui, entre as matérias de competência legislativa privativa da União, a edição de um diploma processual de controle externo de caráter nacional, de iniciativa privativa do Tribunal de Contas da União.

${ }^{4}$ O nome da operação é referência ao Quinto da Coroa, imposto cobrado por Portugal dos mineradores de ouro no período do Brasil Colônia.

${ }^{5} \mathrm{O}$ auditor tem a função de substituir os ministros do TCU, ou os conselheiros do TCEs e TCMs, em caso de férias, licenças, afastamentos legais, vacâncias e impedimentos. No momento da substituição, tem as mesmas garantias e impedimentos do titular.
} 
externo, quando exercido exclusivamente por integrantes que ingressaram por meio de concurso público, o que, em tese, seria mais técnico e menos suscetível a um processo de captura política.

Desse modo, esta pesquisa visa comparar a antiga e a nova composição do TCE-RJ relativamente à produtividade e à efetividade no exercício do controle, através da base de dados públicos obtidos no próprio TCE-RJ.

\section{Metodologia da pesquisa.}

Para a coleta dos dados que foram utilizados na pesquisa, tomou-se como ponto de partida relatórios anuais e trimestrais de atividades do TCE-RJ, disponibilizados em sua base digital $^{6}$, desde o ano de 1998 até 2020. Os relatórios de atividades do TCE-RJ reúnem as principais informações sobre sua atividade, desde as amplas funções de controle externo, como os dados mais relevantes sobre gestão e organização interna.

Como os conselheiros foram afastados em 29 de março de 2017, definiu-se como corte cronológico o primeiro trimestre de 2017. A análise comparativa restringiu-se a períodos anteriores e posteriores ao primeiro trimestre de 2017. A depender do tópico analisado, da adequação e pertinência com a tendência a ser avaliada, realizou-se uma análise trimestral ou anual. Na análise trimestral, cada trimestre está representado da seguinte forma: primeiro o ano e depois o trimestre (ex.: 2017.4, representando o quarto trimestre de 2017).

Os relatórios de atividades expõem o número de processos relatados em Plenário pelo TCE-RJ. Expõem também o número de editais de licitação analisados pelo TCE-RJ, indicando o suposto benefício financeiro do controle do edital. Informam o número de auditorias governamentais, a quantidade e os valores de condenações (multas aplicadas e débitos apurados), e a quantidade de pareceres prévios aprovados e rejeitados dos Chefes do Poder Executivo Municipal e Estadual. Tais dados já podem traçar algum indicativo de mudança de atuação do TCE-RJ.

\section{Pesquisa empírica.}

O afastamento dos cinco conselheiros efetivos do Tribunal ocorreu em 29 de março de 2017. Antes da Operação Quinto do Ouro, o TCE-RJ era composto pelos seguintes membros:

6 Tribunal de Contas do Estado do Rio de Janeiro. Relatórios de Atividades. <https://portalbr.tcerj.tc.br/web/guest/relatorios-de-atividades-do-tce-rj>. Acesso em: 19 dez. 2020. 
José Gomes Graciosa, Marco Antônio Barbosa de Alencar, José Maurício de Lima Nolasco, Aloysio Neves Guedes, Domingos Inácio Brazão e Marianna Montebello Willeman.

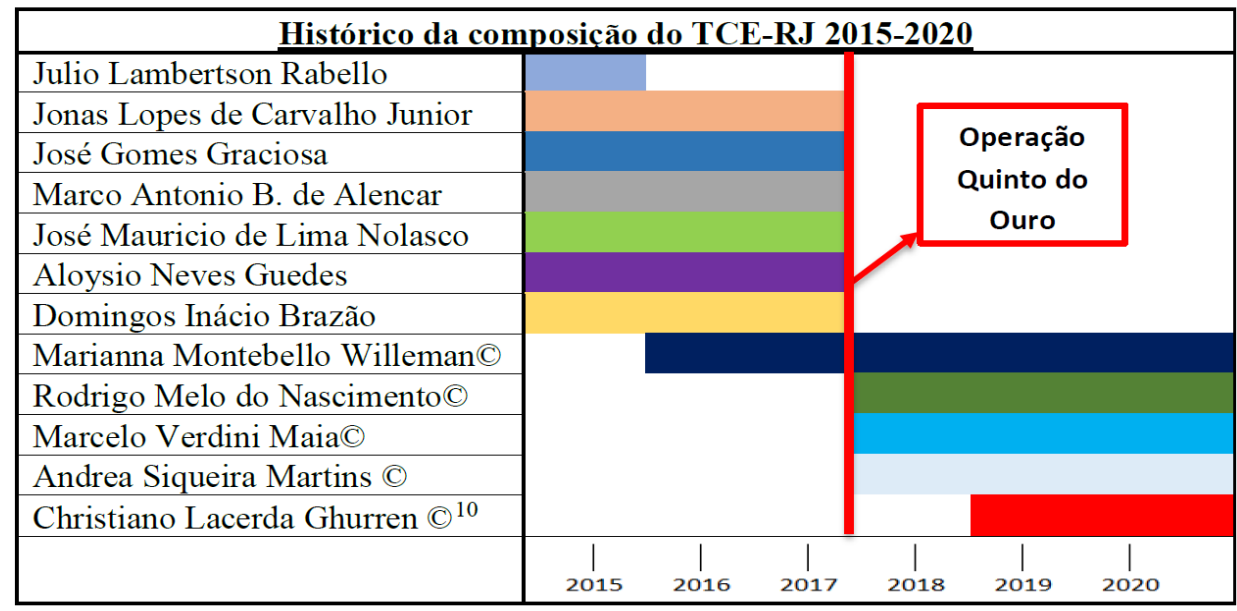

Após o afastamento por determinação judicial, restou apenas Marianna Willeman como Conselheira Efetiva (oriundo do Ministério Público). Passaram a atuar a partir de abril de 2017, como Conselheiros Substitutos, os então auditores concursados Marcelo Verdini Maia, Andrea Siqueira Martins e Rodrigo Melo do Nascimento. Posteriormente, Rodrigo Melo do Nascimento tomou posse, em dezembro de 2017 como Conselheiro Efetivo e ingressou como novo Conselheiro Substituto Christiano Lacerda Ghuerren em março de 2018.

Segue a relação dos dados coletados e compilados.

\begin{tabular}{|c|c|c|c|c|c|c|c|c|}
\hline Itens avaliados & 2014.1 & 2014.2 & 2014.3 & 2014.4 & 2015.1 & 2015.2 & 2015.3 & 2015.4 \\
\hline Municípios & 5.703 & 6.321 & 8.489 & 18.145 & 9.523 & 14.017 & 52.892 & 38.501 \\
\hline Estado & 5.485 & 2.326 & 2.774 & 2.379 & 1.722 & 1.750 & 2.536 & 2.814 \\
\hline $\begin{array}{l}\text { Processos instruídos pelo } \\
\text { Corpo Instrutivo }\end{array}$ & 32.754 & 23.130 & 50.122 & 47437 & 34572 & 48.097 & 39.846 & 88.511 \\
\hline Auditorias Iniciadas & 221 & 154 & 208 & 301 & 15 & 406 & 301 & 92 \\
\hline Ofícios Encaminhados & 9852 & 9199 & 10211 & 12276 & 11008 & 13264 & 13875 & 11578 \\
\hline Citacão & 506 & 361 & 456 & 543 & 477 & 755 & 707 & 536 \\
\hline Comunicação & 8.547 & 8.065 & 8.741 & 10.755 & 9.822 & 11.172 & 11.779 & 9.943 \\
\hline Notificacão & 799 & 773 & 1.014 & 978 & 709 & 1.337 & 1.389 & 1.099 \\
\hline Percentual Citação Total & $5,14 \%$ & $3,92 \%$ & $4,47 \%$ & $4,42 \%$ & $4,33 \%$ & $5,69 \%$ & $5,10 \%$ & $4,63 \%$ \\
\hline $\begin{array}{l}\text { Percentual Notificação } \\
\text { Total }\end{array}$ & $8,11 \%$ & $8,40 \%$ & $9,93 \%$ & $7,97 \%$ & $6,44 \%$ & $10,08 \%$ & $10,01 \%$ & $9,49 \%$ \\
\hline $\mathrm{N}^{\circ}$ débitos imputados & 355 & 112 & 108 & 283 & 236 & 308 & 263 & 89 \\
\hline $\begin{array}{l}\text { Valor dos débitos } \\
\text { imputados }\end{array}$ & R\$21.388.078,85 & $\mathrm{R} \$ 6.267 .084,74$ & R\$ 15.688 .992 .98 & $\mathrm{R} \$ 37.182 .786,18$ & R\$ $19.818 .604,80$ & R\$26.961.937,29 & $\mathrm{R} \$ 28.828 .207,04$ & $R \$ 22.060 .709,06$ \\
\hline
\end{tabular}




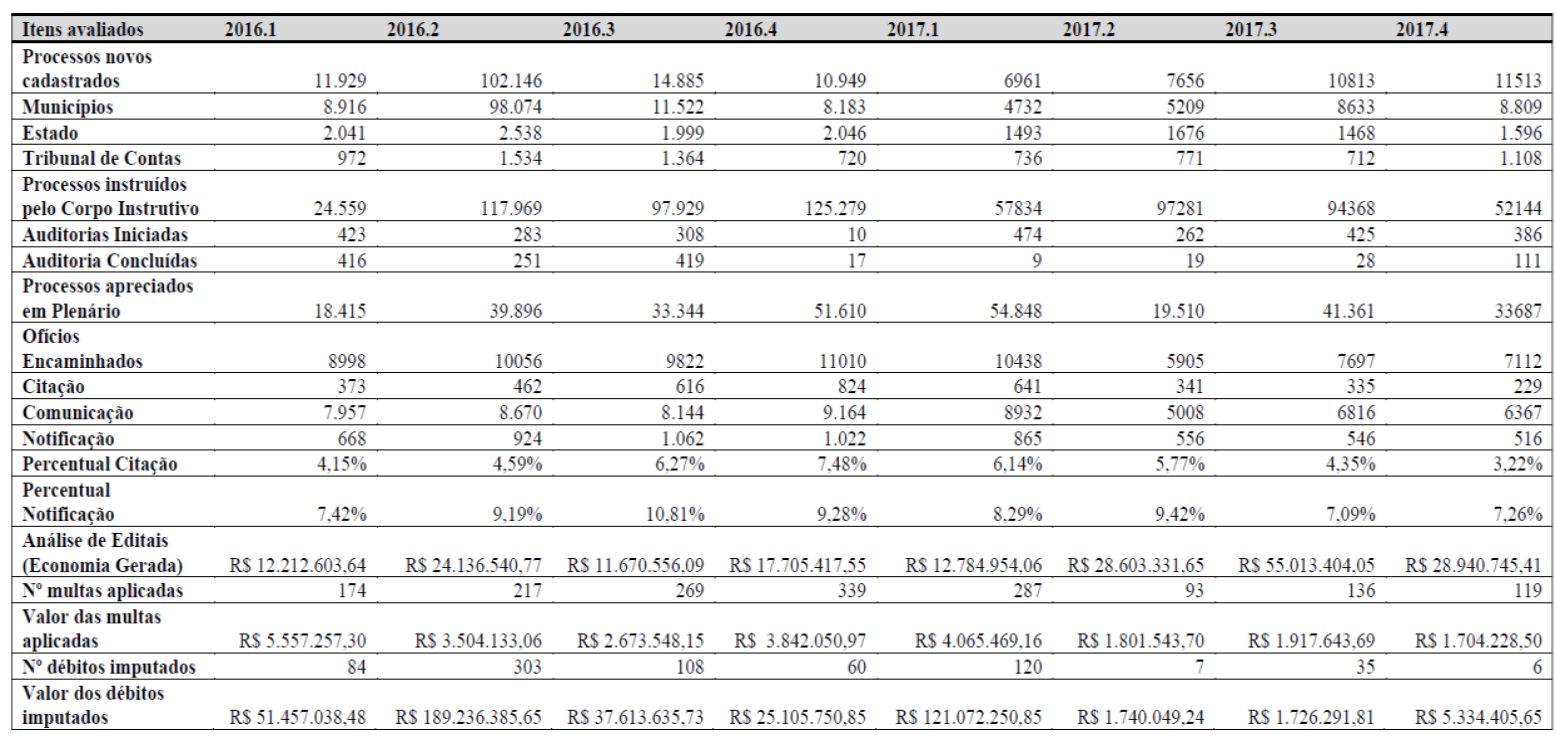

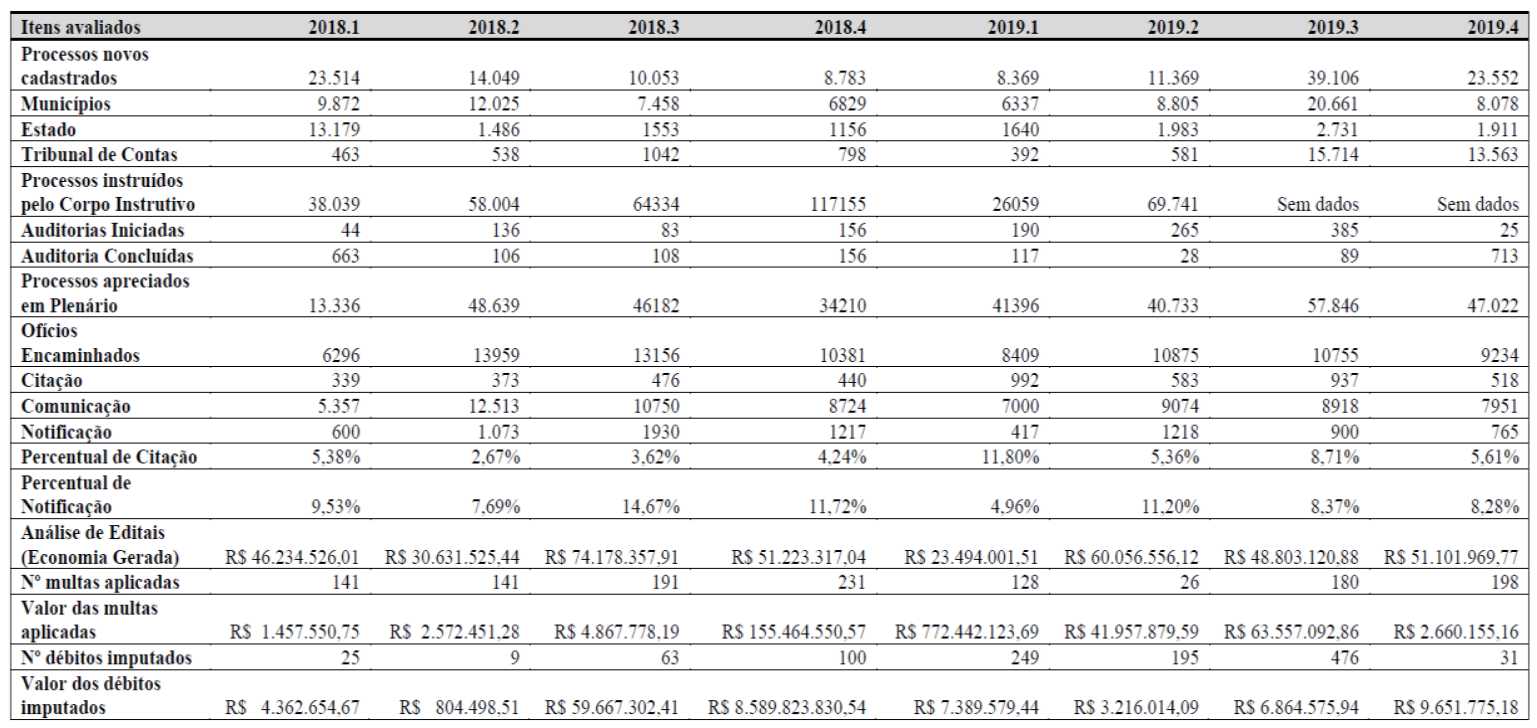

As mudanças na atuação do TCE-RJ foram avaliadas nas seguintes dimensões: (i) produtividade $^{7}$; (ii) efetividade ${ }^{8}$; e, por fim, (iii) estrutura ${ }^{9}$.

\footnotetext{
${ }^{7}$ Em relação à quantidade de processos que ingressaram, quantidade de processos instruídos, quantidade de auditorias, quantidade de processos julgados pelo plenário.

8 Nesta dimensão tratou-se analisar subdimensões relevantes, como a economia gerada; o número de notificações e citações; a quantidade de multas aplicadas; o valor das multas aplicadas; o número de débitos imputados; o valor dos débitos imputados; o número de pareceres prévios dos Prefeitos rejeitados; e alteração da aprovação dos pareceres prévios do Governador do Estado do Rio de Janeiro.

${ }^{9}$ Trata-se de parâmetro relacionado à estrutura interna do TCE-RJ, ou seja, dos instrumentos internos de controle. Nesta dimensão, não restou possível fazer uma comparação quantitativa entre o antes e depois, razão pela qual foi apontada mudanças qualitativas de alteração estruturais após 2017 que contriburam para modernizar o TCE-RJ, inclusive trazendo maior transparência.
} 


\subsection{Produtividade.}

O parâmetro da produtividade para o escopo desta pesquisa pode ser compreendido como a razão entre os fatores de produção (mão-de obra, no caso, os Conselheiros), o resultado (volume de processos julgados, volume de casos analisados pelo Corpo Instrutivo, etc) e o tempo (FUNDAÇÃO GETULIO VARGAS, 2018) Assim, foi avaliado, através de um método comparativo, se a alteração dos fatores analisados impactou o resultado, durante um determinado período de tempo.

Deve-se admitir que há risco de vieses na avaliação da produtividade pelo número de processos julgados. Primeiramente, existe uma grande diversidade de temas que são julgados pelo TCE-RJ ${ }^{10}$, nesta toada, a quantidade ou os valores envolvidos de casos julgados isoladamente analisados não necessariamente reflete a existência de uma maior ou menor qualidade nos julgamentos.

No caso de um Tribunal de Contas (TC), não obrigatoriamente o Conselheiro do Tribunal de fato que realiza a maior carga de trabalho. Existe inicialmente um corpo instrutivo, eminentemente técnico, que faz a análise prévia do processo. Posteriormente, o processo é remetido para o Ministério Público do Tribunal de Contas, que faz uma manifestação. Em seguida, os Conselheiros, com sua própria equipe de assessores, avaliam cada processo para, posteriormente, colocarem em plenário e efetuarem um voto.

O Conselheiro pode optar por seguir integralmente a manifestação do Corpo Instrutivo e do Ministério Público. Com isso, os Conselheiros podem acolher a manifestação do Corpo Instrutivo, sem entrar nos detalhes de cada processo.

Cada processo pode ter detalhes não só técnicos, mas também jurídicos relevantes e a manifestação do Conselheiro pode ser primordial, para inserir uma análise acurada de cada caso. Ademais, compete à Corte de Contas realizar uma auditoria nas contas da Administração Pública, tarefa que exige um elevado nível de detalhamento técnico.

\footnotetext{
${ }^{10}$ Como exemplo da lista da natureza dos processos julgados pelo TCE-RJ, casos de Aposentadoria, Pensão, Reforma, Transferência para a Reserva, Fixação da Remuneração dos Agentes Políticos, Ato de Dispensa de Licitação, Ato de Inexigibilidade de Licitação, Concurso Pública, Contratos, Convênios, Denúncia, Representação; Edital de Licitação e Pregão, Prestação e Tomada de Contas, Processo Especial de Cobrança Executiva, Promoção, Relatório de Auditoria Governamental, Relatório de Gestão Fiscal, Relatório Resumido da Execução Orçamentária.
} 
Por outro lado, há de se admitir que os Conselheiros, além de exercerem a jurisdição controladora, atuam na administração do TCE-RJ. Com a troca dos Conselheiros, uma "nova administração" surgiu, o que torna relevante avaliar como essa "nova administração" tem atuado na gestão do Tribunal.

Importante fato que pode impactar nos resultados é que antes da Operação Quinto do Ouro, o TCE-RJ era composto oficialmente de sete Conselheiros, apesar de um ter se ausentado desde dezembro de 2016. A nova composição inicialmente era de quatro membros e passou a ter cinco integrantes a partir de março de 2018. Esse fato invariavelmente impacta na atuação de Tribunal com poucos membros.

A avaliação da produtividade durante um determinado período pode não ser a forma mais eficaz de avaliar a qualidade do Tribunal, entretanto, considerando a dificuldade de busca no sistema de dados do TCE-RJ, aliado ao subjetivismo que uma análise qualitativa sobre o teor das decisões possa ocasionar, restou avaliado nesta parte do trabalho: (i) a quantidade de processos novos cadastrados; (ii) a quantidade de processos instruídos pelo corpo instrutivo; (iii) a quantidade de auditorias iniciadas e finalizadas; (iv) a quantidade de processos apreciados pelo plenário.

\subsubsection{Quantidade de processos novos cadastrados.}

Observa-se que ocorreu uma diminuição de processos cadastrados, com média de 25.415 no período anterior a mudança, e a média de 14.343 no período posterior. Ademais, mesmo desconsiderando o trimestre 2016.2, que representou um número expressivo, fora da curva no número de processos novos (102.146), observa-se uma diminuição no número de novos processos cadastrados no TCE-RJ nos últimos anos.

Nesse sentido, possivelmente, com um acervo menor do número de processos há maior probabilidade de um exame mais acurado em cada um dos casos por parte do TCE-RJ, seja pelos conselheiros, seja pelo corpo instrutivo.

\subsubsection{Quantidade de processos instruídos pelo corpo instrutivo.}

A análise dos processos instruídos pelo Corpo Instrutivo é relevante, uma vez que apesar de ter autonomia em relação ao Plenário para o proferimento de manifestações, sua organização é disciplinada pela Presidência do TCE-RJ. Dessa forma, a alteração na 
composição do Plenário do Tribunal pode influenciar também a organização e produtividade do Corpo Instrutivo.

A média de processos instruídos pelo corpo instrutivo de 2015.1 até 2017.1 foi de 70.510 , enquanto a média posterior passou a ser de $68.569^{11}$. Os relatórios de atividades de 2019.3 e 2019.4 não informaram o quantitativo de processos instruídos pelo Corpo Instrutivo, por isso espaço temporal de análise deste quesito foi reduzido.

Como a produtividade do corpo instrutivo foi bastante próxima entre os dois períodos analisados, não é possível extrair tendências ou conclusões precisas sobre alterações de produtividade quanto a este quesito. É possível considerar que a diminuição de novos processos cadastrados pode ter impactado na redução da produtividade do Corpo Instrutivo.

Assim, é necessário aferir outros dados em conjunto, para extrair algum tipo de conclusão mais precisa a respeito da produtividade.

\subsubsection{Quantidade de auditorias iniciadas e finalizadas.}

Trata-se de um relevante quesito, que corresponde a função fiscalizadora da Corte de Contas, capaz de demonstrar não somente um grau de produtividade, como até mesmo um caráter de aumento de efetividade no controle. Como os dados quantitativos não são capazes de demonstrar os resultados das auditorias realizadas, optou-se por inserir esse quesito na análise da produtividade do Tribunal.

Este quesito de quantidade de auditorias restou subdivido em auditorias iniciadas no período e auditorias finalizadas no período.

Depreende que a média de auditorias iniciadas e concluídas antes do primeiro trimestre de 2014 até o primeiro trimestre de 2017, foi respectivamente de 245 e 204. Por sua vez, após o afastamento, relativamente ao período do segundo trimestre de 2017.2 até o quatro trimestre de 2019, a média de iniciadas e concluídas foi respectivamente de 214 e 194.

Em que pese não ser possível apontar significativa alteração de tendência do Tribunal pela análise das médias, é possível depreender que em alguns trimestres após o afastamento, precisamente em 2018.1 e 2019.4, ocorreram as maiores conclusões de auditorias entre todos os trimestres analisado, 663 e 713, respectivamente.

\footnotetext{
${ }^{11}$ Informa-se que o TCE-RJ não disponibilizou esses dados a partir do terceiro trimestre de 2019.
} 


\subsubsection{Quantidade de processos apreciados pelo plenário.}

Este quesito corresponde aos processos que são analisados no Plenário do TCE-RJ, após manifestação do Corpo Instrutivo e do Ministério Público do Tribunal de Contas. O processo é distribuído para um Conselheiro relator, o qual cabe proferir seu voto, o qual pode ser acompanhado ou rechaçado pelos demais membros do colegiado.

A média de processos julgados, antes da mudança de composição foi de 37.287, enquanto a média posterior foi de 38.538. Em que pese os dados indicarem que houve um aumento global no número de processos julgados com a nova composição do TCE-RJ, ocorreu uma baixa variação.

Por sua vez, conjugando tal indicador com o número de processos novos cadastrados no Tribunal (gráfico i), depreende-se que a relação acervo novo versus julgamentos novos pelo plenário, há uma melhor relação no período posterior ao afastamento, diante do menor número de processos ingressantes no Tribunal no período posterior e mudança de composição e quantidade de processos apreciados pelo plenário similar.

Após 2018.1 - um ano após a operação - já é possível reconhecer a ocorrência de um aumento mais significativo no número de casos apreciados pelo plenário do Tribunal (média de 47.029, se considerar apenas o período de 2018.2 até 2019.4), que representa quase $30 \%$ de aumento em relação ao período anterior ao afastamento.

Cabe salientar que, após o afastamento no ano de 2017, o TCE-RJ ficou com apenas quatro Conselheiros atuando, sendo que o quinto Conselheiro, Cristiano Ghurren tomou posse apenas em 9 de março de 2018, o que, conforme já exposto, invariavelmente impacta a quantidade global de processos analisados pelos TCE-RJ no ano.

\subsection{Efetividade.}

O parâmetro da efetividade diz respeito ao real exercício do controle pela Corte de Contas, ou seja, o controle no mundo fático, de forma a cumprir com seu objetivo. O controle efetivo pelo TCE-RJ seria aquele de fato exercido, tal como previsto no ordenamento jurídico (art. 70 e 71 da Constituição Federal).

Considerando que o controle exercido pelos TCs, através de um movimento jurisprudencial, se encontra em crescente ampliação nos últimos 20 anos, movimento que tem causado dificuldades para o funcionamento da Administração Pública e receios para os 
gestores públicos ("apagão das canetas""12) (VERNALHA, 2016), a avaliação e mensuração da efetividade do controle se torna algo extremamente complexo e demasiadamente árduo.

Como forma de objetivar a avaliação, de forma a tornar possível aferir tendências, optou-se por avaliar os seguintes quesitos: (i) notificações e citações realizadas; (ii) economia gerada na análise dos editais de licitação; (iii) multas aplicadas; (iv) débitos imputados; (v) a quantidade de pareceres prévios do Executivo rejeitados.

\subsubsection{Notificações e citações realizadas.}

De acordo com o Regimento Interno do TCE-RJ, existem três formas de chamar o jurisdicionado ou o interessado aos autos: (i) comunicação, na qual se convoca para prestar esclarecimentos ou apresentar documentos; (ii) notificação, quando, ao analisar um ato do jurisdicionado, verifica-se a o indício de irregularidades ou ilegalidades, sem que haja débito apurado, facultando a apresentação de razões de defesa; (iii) citação, quando o Tribunal considera haver irregularidades ou ilegalidades e convoca o responsável, para apresentar razões de defesa ou recolher o débito apurado ${ }^{13}$. Pode-se observar que existe uma gradação, sendo a comunicação um simples chamamento ao processo para apresentação de documentos e/ou esclarecimentos ${ }^{14}$, enquanto na notificação, já há um indício de alguma irregularidade ou ilegalidade, e na citação o Tribunal já considera haver constado uma ilegalidade.

Assim, correspondendo a quantidade de citações, notificações e comunicações sobre cada processo analisado, é possível averiguar alguma relação direta com efetividade no exercício do controle pelo TCE-RJ.

Primeiramente, optou-se por realizar um estudo do número anual de notificações e citações realizados pelo TCE-RJ. Dessa forma, restou feita uma análise entre os três anos anteriores (2014-2016) e os três anos posteriores (2017-2019). A média de notificações de 2014 a 2016 foi de 3924, enquanto a média de citações no mesmo período foi de 2.205. Já

\footnotetext{
${ }^{12}$ Eventual rigor extremado dos órgãos de controle é o fenômeno conhecido como "apagão das canetas", na qual Fernando Vernalha assim dispõe. "Decidir sobre o dia a dia da Administração passou a atrair riscos jurídicos de toda a ordem, que podem chegar ao ponto da criminalização da conduta. Sob as garras de todo esse controle, o administrador desistiu de decidir. Viu seus riscos ampliados e, por um instinto de autoproteção, demarcou suas ações à sua "zona de conforto"

${ }^{13}$ Regimento interno do TCE-RJ em seu art. 26 dispõe sobre o chamamento ao processo, do responsável ou interessado, por comunicação, notificação ou citação, conforme o caso.

${ }^{14} \mathrm{O}$ chamamento ao processo previsto no Regimento Interno do TCE-RJ não deve ser confundido com a modalidade de intervenção de terceiros prevista no Código de Processo Civil.
} 
sobre o período de 2017 a 2019, a média de notificações foi de 1.876, ao passo que a média de citações no mesmo espaço de tempo foi de 3.726.

Ao separar os números por trimestre, a média de notificações de 2014.3 a 2017.1 foi de 1.006, enquanto a média de citações no mesmo período foi de 580. Já sobre o período de 2017.2 a 2019.4, a média de notificações foi de 885 , enquanto a média de citações no mesmo espaço de tempo foi de 505.

Apesar do número menor de notificações e citações no período posterior ao afastamento dos conselheiros, cumpre recordar que a nova composição se restringia à quatro conselheiros e, a partir de março de 2018, com cinco, com o ingresso de mais um conselheiro substituto.

Computando-se os dados a partir de 2018.2 até 2019.4, a média de citações neste período foi de 617, enquanto a média de notificações correspondeu a quantia de 1.074. Tais números são superiores à média anterior ao afastamento, o que pode indicar um traço de maior efetividade no controle com a nova composição. Entretanto, é importante ressaltar que é apenas um indício de um controle mais efetivo.

É conveniente também analisar os percentuais de notificações e citações em relação ao total de ofícios encaminhados aos jurisdicionados. As médias, antes do afastamento, ficaram em citação de $5,10 \%$ e notificação de $8,94 \%$. Posteriormente ao afastamento, ficaram as médias de citação em 5,52\% e de notificação em 9,11\%. Depreende-se que ocorreu então, ligeira tendência de alta após a nova composição no número de citações e notificações. Se a análise se restringir ao período de 2018.2 até 2019.4, a média de citações foi de $6 \%$, e de notificações, 9,56\%. Este último momento indica uma possível alta da efetividade do controle pelo TCE-RJ.

\subsubsection{Economia gerada na análise dos editais de licitação.}

O TCE-RJ exerce função de controle prévio dos editais de licitação. Após a atuação do TCE-RJ em diversos editais, a Corte tem o costume de divulgar o impacto econômico que gerou, através do exercício de controle. É possível realizar críticas ao exercício de controle prévio dos editais ${ }^{15}$, bem como ao critério subjetivo de economia gerada adotado pelo TCE.

\footnotetext{
${ }^{15}$ Não necessariamente a análise do Edital pelo TCE-RJ sempre significa um benefício econômico público. Os
} 
No entanto, diante do escopo descritivo deste trabalho e da relevância dos indicadores, entendemos relevante apontar as tendências sobre a economia gerada, tendo sido produzido dois gráficos sobre a questão, um por trimestre e outro por ano.

A média por trimestre antes do afastamento foi de $\mathrm{R} \$ 40.270 .795,38$, enquanto a média posterior ao afastamento foi de $\mathrm{R} \$ 45.298 .259,62^{16}$, representando significativo aumento. Já a média dos três anos anteriores aos afastamentos (2014, 2015 e 2016) foi de R\$ 170 milhões de reais, enquanto a média nos três anos após os afastamentos correspondeu a quantia de R\$ 189 milhões.

Seja como for, mesmo que seja extraído o ponto fora da curva ocorrido em 2014.4, o aumento após 2017.1 é ainda expressivo. Tais resultados demonstram que a nova composição, mesmo com uma quantidade menor de integrantes, foi mais rigorosa na análise dos editais de licitação, o que reforça a indicação de uma maior efetividade quanto a esse quesito.

\subsubsection{Multas aplicadas.}

O TCE-RJ tem a competência de impor aos seus jurisdicionados multas, decorrente da violação não somente das normas contábeis, financeiras, orçamentárias, operacionais e patrimoniais, mas também por inobservância de prazos e descumprimento de decisões do Tribunal, conforme previsto no art. $3^{\circ}$, XIII, de sua Lei Orgânica. Trata-se de um amplo poder sancionatório conferido à corte de contas fluminense, como forma de conformar as condutas de seus jurisdicionados. Avaliar o quantitativo de multas aplicadas, cumulado com o valor das multas aplicadas, pode ser capaz de expressar aspectos da efetividade do controle exercido pelo TCE-RJ.

Em relação ao quantitativo de multas, de 2010 até 2017 houve uma queda progressiva, sendo que em 2017 a quantidade de multas emitidas foi praticamente 1/3 das multas emitidas em 2010. Somente a partir do ano de 2018 os números passaram a subir, contudo, em quantidade inferior ao comparado aos anos antes da mudança de composição. A partir de um cálculo trimestral, referente ao período de 2014.3 até 2017.1, a média trimestral de multas

tribunais de conta visam proteger o erário público e busca trazer menor gasto de recursos públicos. Entretanto, em muitos casos o TCE-RJ se arvora no papel do administrador, determinando de mérito nos editais, alterações de mérito.

${ }^{16}$ Utilizou-se os exatos valores disponibilizados pelo TCE-RJ de forma que os autores preferiram não efetuar correção monetária. 
aplicadas era de 270. Já em relação ao período de 2017.2 até 2019.4, a média passou a ser de 144, o que demonstra a redução do quantitativo.

A respeito do valor das multas aplicadas, enquanto a média anual de 2014 até 2016 era de 11 milhões de reais ${ }^{17}$, a média anual de 2017 até 2019 chegou a 64 milhões. Somente no ano de 2018, o quantitativo total de multas foi de 164 milhões. De acordo com os dados trimestrais, a média trimestral de 2014.4 até 2017.1, referente ao valor das multas aplicadas, representava a quantia de $\mathrm{R} \$ 3.225 .380,47$. Por sua vez, em relação ao período de 2017.2 até 2019.4, a média trimestral passou a ser de $\mathrm{R} \$ 95.491 .181,63$. Nos relatórios de atividades, não foi possível observar quais processos geraram o expressivo crescimento no valor das multas. De qualquer forma, trata-se de um valor altamente expressivo, considerando que a multa não visa recompor o erário, mas punir o infrator.

É possível depreender desses dados que apesar do quantitativo ter diminuído, as multas aplicadas foram extremamente mais rigorosas, o que representa uma mudança de postura. É necessário análise de outros índices para indicar uma real mudança de postura do TCE-RJ.

\subsubsection{Débitos imputados.}

Débito imputado diz respeito ao valor que o TCE-RJ apura como decorrente de dano ao erário, o qual deve ser devidamente ressarcido aos cofres públicos. Como decisões não definitivas nos processos de controle podem imputar débitos, não está claro nos relatórios do TCE-RJ se tais débitos são oriundos de decisões definitivas, não sujeitas mais a recursos. Desse modo, a falta de transparência quanto ao trânsito em julgado pode levar a conclusões errôneas quanto a atuação do TCE-RJ. De qualquer forma, mesmo se tratando de decisões provisórias, uma possível alteração expressiva nos números pode denotar uma mudança na postura da nova composição.

A quantidade de débitos imputados foi reduzida de forma drástica após 2016, ou seja, após a mudança de composição, ocorreu menor quantidade de débitos, mas com valores mais elevados.

\footnotetext{
${ }^{17}$ Utilizou-se os exatos valores disponibilizados pelo TCE-RJ de forma que os autores preferiram não efetuar correção monetária.
} 
No período analisado antes da mudança, de 2014 a 2016, a média dos valores imputados era de 160 milhões por ano. De 2017 a 2019, em razão do aumento expressivo no valor da recomposição, a média anual passou a ser de 3 bilhões e 200 milhões. Em 2018, houve um salto extremamente significativo e fora da curva, atingindo um valor total de 8 bilhões e seiscentos milhões de reais de débitos imputados. Não obtivemos todas as razões desse salto significativo, mas é provável que alguns casos importantes impactaram nesse resultado, como o da Linha 4 do Metrô ${ }^{18}$ e da OS na Saúde ${ }^{19}$. Em 2019, essa quantia reduziu para oitocentos milhões de reais, valor ainda bem superior aos demais anos anteriores (20142016). Assim, mesmo retirando o ponto fora da curva ocorrido em 2018 ainda se verifica um aumento após 2017. De 2014.3 até 2017.1, a média trimestral de débitos imputados correspondia à quantia de $\mathrm{R} \$ 52.275 .118,08$. Com o ingresso da nova composição, de 2017.2 até 2019.4, a média trimestral passou a ser de R $\$ 790.052 .816,13$. Tratou-se também de um crescimento exponencial no valor de débito imputado.

\subsubsection{Quantidade de pareceres prévios.}

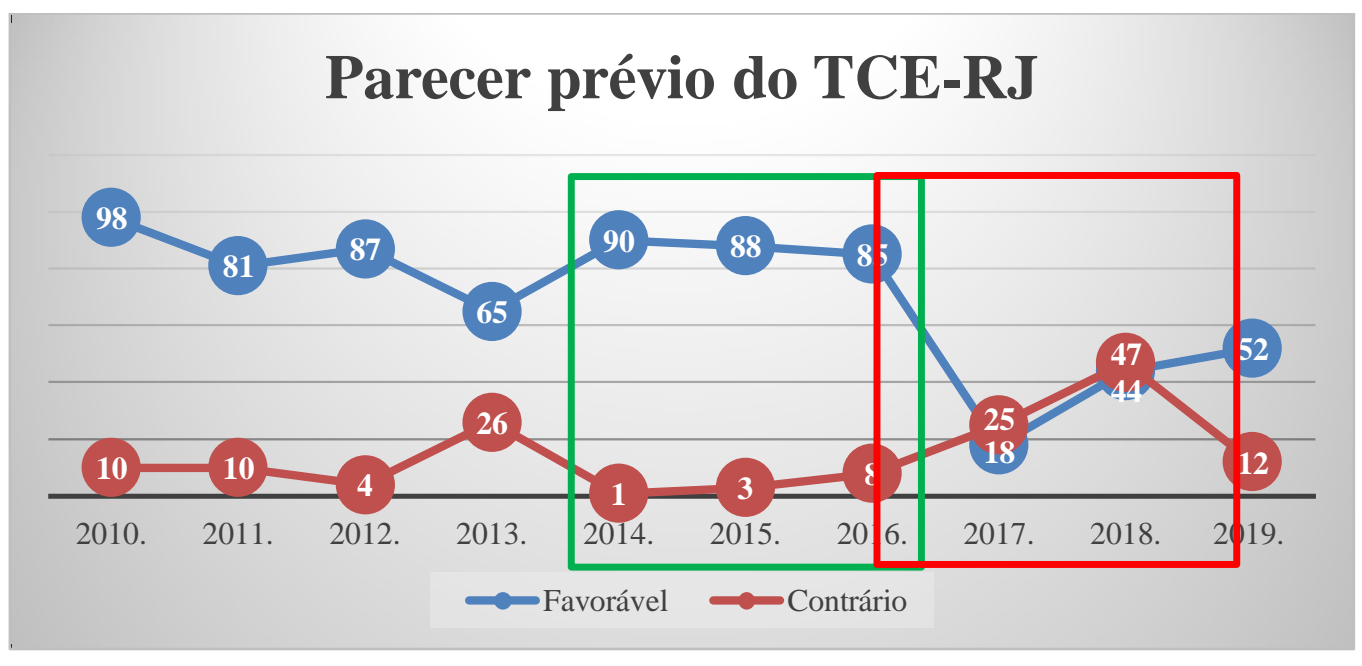

Compete aos TCs emitirem um parecer prévio relativo às contas dos Chefes do Poder Executivo. Apesar do julgamento das contas pelo Legislativo ser um ato político, com a rejeição das contas de um governo é possível gerar a abertura de um processo de

\footnotetext{
${ }^{18}$ Decisão proferida na sessão de 12/19/2018, referente ao Processo ${ }^{\circ} 101.387-5 / 18$, que versa sobre a Tomada de Contas Especial Ex Officio, decorrente da conversão de Auditoria Governamental realizada na Companhia de Transportes Sobre Trilhos do Estado do Rio de Janeiro (Riotrilhos).

${ }_{19}^{19}$ Decisão proferrida na sessão de 27/11/2018, referente ao Processo ${ }^{\circ} 100.266-5 / 08$, que versa sobre uma Tomada de Contas Especial, visando apurar se os serviços realizado por cooperativados nas unidades hospitalares estaduais foram efetiva e economicamente prestados.
} 
impeachment, com base no art. 85 da CFRB (LIMA, 2016). A situação é mais severa no caso dos Prefeitos, pois somente por decisão de dois terços dos membros da Câmara Municipal deixará de prevalecer o parecer prévio, emitido pelo TCE-RJ (art. 124, §2º da Constituição do Estado do Rio de Janeiro).

Relevante alteração quantitativa entre os anos 2017 e 2019 se deu em relação ao parecer prévio feito pelo TCE-RJ em cada ano das contas do Chefe do Executivo Municipal.

Depreende-se que, historicamente, a quantidade de pareceres favoráveis sempre foi muito superior a quantidade de pareceres desforráveis ${ }^{20}$, chegando a casos de 90 para 1 (2014), 88 para 3 (2015) e 85 para 8 (2016) nos três anos anteriores.

No entanto, no ano da mudança de composição em 2017, foi constatado que o TCE-RJ apresentou volume muito inferior de pareceres (43), enquanto nos anos anteriores sempre foi superior a 90 pareceres.

Ademais, em 2017 a relação entre pareceres favoráveis e desfavoráveis também se alterou drasticamente, de 18 para 25 , sendo a primeira vez que ocorreu a predominância de pareceres desfavoráveis durante todo o período analisado. Tal situação se repetiu no ano de 2018.

Outro dado extremamente relevante ocorreu em relação a aprovação das contas do Governador do Estado. A partir da prisão dos cinco conselheiros, 2017 em diante, todas as contas do Governador passaram a ser rejeitadas pelo TCE-RJ. Cabe salientar que a Corte de Contas apenas emite um parecer prévio sobre as contas do Executivo que, posteriormente, são analisadas pelo Legislativo, o qual caberá a palavra final.

\subsection{Estrutura.}

Apenas para o escopo deste trabalho, deve-se compreender estrutura como os instrumentos ou meios utilizados pelo órgão controlador para exercer sua função controladora. A estrutura diz, então, respeito aos processos e procedimentos utilizados para implementar o controle, englobando quesitos como publicidade e transparência. Trata-se de um quesito relevante para avaliar, através de um olhar interno, possíveis tendências de

\footnotetext{
${ }^{20}$ Destaca-se que o parecer do TCE-RJ não é vinculante, cabendo ao órgão legislativo respectivo (Assembleia Legislativa do Estado do Rio de Janeiro no caso do Governador, e Câmara de Vereadores no caso dos municípios) o julgamento final das contas baseado no parecer técnico emitido.
} 
alteração no exercício do controle externo. Assim, além da análise descritiva sobre a produtividade do TCE-RJ ao longo dos anos, relevante destacar alterações qualitativas estruturais e de conjunturas que ocorreram após a operação quinto do ouro no TCE-RJ, e que podem ter impacto direto no trabalho do Tribunal.

Dentro deste tópico, após as análises dos relatórios de atividade do TCE-RJ, bem como do Plano Estratégico do tribunal ${ }^{21}$, optou-se por avaliar algumas mudanças pontuais na estrutura consideradas mais relevantes, que possam demonstrar alguma tendência de mudança, após a entrada da nova composição.

Primeiramente, importante ressaltar que o TCE-RJ antes da mudança na composição já promovia mudanças em suas estruturas, como forma de modernizar o exercício do controle externo. É possível citar que, em 2013, já havia o planejamento de implementar o processo eletrônico no TCE-RJ, o qual passou a ser adotado a partir de março de 2014 em relação aos processos relacionados à aposentadoria e posteriormente foi regulamentado de maneira ampla em dezembro de 2014. Após a implementação dessa alteração, o tempo médio de tramitação de editais caiu $16 \%$ entre 2014 e 2015 , do momento em que o edital é recebido no Tribunal até a sua apreciação em plenário.

No período anterior ao afastamento, já havia uma preocupação no TCE-RJ sobre a necessidade de uma consolidação da jurisprudência, como demonstrado no Planejamento Estratégico de 2016-2019, ao mencionar como ponto fraco do tribunal a "sumularização das decisões plenárias incipiente (ou inexistente)",22.

Já após o afastamento, é possível mencionar que o TCE-RJ passou a ter um plenário virtual, com o intuito de retirar a necessidade de submissão ao plenário presencial e acelerar a prestação jurisdicional. As partes ainda mantiveram a opção de solicitar sustentação oral, pois gera a imediata submissão ao plenário presencial ${ }^{23}$.

Não se nega que as sessões deliberativas sempre foram públicas, no entanto, a partir de maio de 2017, o TCE-RJ passou a disponibilizar as sessões plenárias através da plataforma

21 Tribunal de Contas do Estado do Rio de Janeiro. Plano Estratégico 2016-2019.<https://portalbr.tcerj.tc.br/documents/10180/1226608/Plano\%20Estrat\%C3\%A9gico\%202016-

2019\%20A4\%20DEF\%20SITE.pdf>. Acesso em: 20 dez. 2020.

${ }_{22}^{2}$ Ibidem

${ }^{23}$ Instituído a partir da Deliberação n ${ }^{\circ}$ 296, de 08 de novembro de 2018, do TCE-RJ. 
digital Youtube. Dessa forma, aumenta-se a transparência e o escrutínio público sobre a tomada de decisões, afinal, "a luz do sol é o melhor desinfetante" (Louis Brandeis) ${ }^{24}$.

A Corte de Contas do Estado do Rio de Janeiro passou a ter súmula de jurisprudência (sendo a primeira súmula editada em 2018) de forma a publicizar, através de verbetes, o registro sobre a interpretação pacífica ou majoritária adotada pelo referido Tribunal, mitigando que decisões sejam julgadas "pela capa dos autos".

O TCE-RJ também passou a ter desde janeiro de 2020 boletim de jurisprudência, contendo informações sintéticas de decisões relevantes proferidas pela Corte sob o prisma jurisprudencial, de modo a facilitar o acesso a todos interessados sobre os entendimentos predominantes do Tribunal.

Também ocorreu a formação de força tarefa entre o TCE-RJ e o Ministério Público do Estado do Rio de Janeiro focada em gastos envolvendo a pandemia do Covid-19. Tratou-se de cooperação técnica entre órgãos de controle que visa analisar detidamente atos e contratos relativos ao enfrentamento da COVID- $19^{25}$.

Destaca-se que o referido instrumento para troca de informações entre as instituições públicas incumbidas do controle externo da administração pública no âmbito territorial do Estado do Rio de Janeiro, cuja importância restou potencializada no contexto de múltiplas contratações emergenciais pelo poder público em razão da pandemia do novo coronavírus, culminou, inclusive, com o afastamento do Governador do Estado do Rio de Janeiro Wilson Witzel, além diversos Secretários Estaduais.

Isto é, elementos probatórios obtidos pela força tarefa TCE-RJ/MP serviram de fundamento para a decisão da Corte Especial do Superior Tribunal de Justiça que afastou o governador. Ademais, estes mesmos elementos foram suscitados como razões para o afastamento decorrente do processo de impeachment por decisão do Parlamento Estadual fluminense.

Por fim, é possível ressaltar que de abril de 2017 a setembro de 2020 (41 meses), foram editadas 49 Deliberações, regulando os mais variados temas, enquanto no período de

\footnotetext{
${ }^{24}$ Frase atribuida ao Juiz da Suprema Corte Americana Louis D. Brandeis há quase um século (1933) e até hoje propagada "Sunlight is said to be the best of disinfectants; electric light the most efficient policeman."

${ }^{25}$ A Força Tarefa de Atuação Integrada na Fiscalização das Ações Estaduais e Municipais de Enfrentamento à COVID-19 (FTCOVID-19/MPRJ) foi criada pela Resolução GPGJ no 2.335, de 7 de abril de 2020.
} 
setembro de 2013 até março de 2017 (41 meses), foram editadas apenas 10 Deliberações. Sem analisar o aspecto qualitativo de tais alterações, a nova composição registrou um aumento do exercício da função normativa do $\mathrm{TC}^{26}$.

\section{Análise global dos resultados.}

Considerando que o TCE-RJ se tornou um "laboratório real" para comparar uma composição política com uma composição de cunho eminentemente técnico, após a análise descritiva e com caráter primordialmente quantitativo, restou possível depreender algumas mudanças de padrões do TCE-RJ após a Operação Quinto do Ouro.

Quanto ao aspecto da produtividade, os dados apresentados não são claros em demonstrar se houve uma grande mudança. Chama atenção os dados relativos aos processos apreciados em plenário a partir do momento que a Corte com a nova composição passa a ter cinco membros, sendo possível observar um possível aumento da produtividade. Entretanto, tais dados não são capazes de demonstrar claramente uma relação de causa e efeito da mudança da composição e aumento de produtividade. É possível considerar que a implementação do plenário virtual e o assentamento do processo eletrônico tenha contribuído para a agilidade das análises. Assim sendo, a conclusão quanto a este parâmetro analisado é sobre a impossibilidade de demonstrar uma tendência clara de mudança.

A respeito da efetividade do controle, vários parâmetros foram utilizados na pesquisa. Em relação à análise das notificações e citações, o percentual dessas formas de chamamento ao processo aumentou, o que pode denotar um exercício da atividade de controle com maior rigor. Entretanto, a variação não foi significativa, a ponto de demonstrar uma sólida tendência.

Já em relação às multas aplicadas e débitos imputados, apesar do quantitativo ter reduzido, os valores cresceram significativamente, o que também se apresentou em relação à quantidade e valores de multas, ou seja, diminuiu-se a quantidade e aumentou-se o valor envolvido. Também se observou uma maior economia decorrente de editais após a mudança na composição.

26 Dados estão disponíveis na página da internet do TCE-RJ. <https://www.tcerj.tc.br/cadastropublicacoes/public/deliberacoes>. Acesso em: 20 dez. 2020. 
Neste mesmo movimento, outro dado observado foi uma maior quantidade de pareceres pela reprovação de contas, com destaque a rejeição das contas do Governador do Estado do Rio de Janeiro a partir de 2017 em diante.

O dado qualitativo mais relevante diz respeito a maior reprovação das contas dos Prefeitos e do Governador do Estado. Os dados apresentados apontam uma tendência de maior independência na imposição de sanções mais severas. Tal verificação não é capaz de demonstrar uma relação direta de causalidade, mas essa inclinação chama a atenção para a importância de aprofundar o estudo sobre este tema.

Por sua vez, conforme se depreende da análise dos dados apresentados, diversos outros critérios analisados não apresentaram resultados significativos em decorrência da mudança de composição.

Sob outro ângulo, agora sob uma análise de viés qualitativo sobre mudanças estruturais e de transparência, restou possível observar um salto de 2017 em diante na estrutura do TCE-RJ, após a mudança de composição, que certamente ocasionou maior abertura e transparência do Tribunal de Contas, com destaque à edição de súmula de jurisprudência e transmissão pela internet das sessões.

\section{Conclusão.}

O trabalho focou em uma análise sob eixo majoritariamente descritivo, de forma que qualquer discussão jurídica e política que se pretenda sobre mudança na forma de composição dos TCs, bem como sobre uma maior ou menor probabilidade de captura política diante da forma de ingresso no TCs, deve, obrigatoriamente, perpassar por uma análise isenta sobre dados, assim como por uma análise qualitativa das decisões, parte esta que não foi objeto do presente estudo.

Através dos resultados apresentados no estudo não se pode peremptoriamente concluir que o TCE-RJ antes da mudança da sua composição era um TC eminentemente "capturado" e que perdeu sua captura política após a mudança de composição.

Alguns dados não apresentaram alterações substanciais, enquanto outros dados apontaram uma significativa alteração. O dado mais relevante observado foi o aumento significativo do número de pareceres prévios contrários sobre as contas de governo dos municípios fiscalizados pelo TCE-RJ. Ademais, após a alteração da composição, as contas de 
governo do Estado do Rio de Janeiro passaram a ser rejeitadas pela Corte de Contas fluminense.

Nesse cenário, é certo que o presente estudo deverá servir de ponto de partida para novas investigações, seja sobre a qualidade das decisões antes e após a nova formação, seja ao longo dos anos, considerando que se tratou de período temporal ainda reduzido, já que a mudança da composição no momento da produção deste trabalho não possui nem quatro anos. Em suma, espera-se que este trabalho seja um nascedouro para que investigações possam ser complementadas e aperfeiçoadas.

\section{Referências.}

DA SILVA, Rodrigo Monteiro. A alteração na forma de escolha de membros dos tribunais de contas estaduais por meio de proposta de emenda constitucional oriunda de iniciativa popular: uma interpretação democrática do artigo 75 da Constituição Federal. In: Revista Ministério Público de Contas do Paraná, no 7, ano III, Nov. 2017/Mai. 2018.

FUndAÇÃO GETUlio VARGAS. Políticas públicas do Poder Judiciário: uma análise quantitativa e qualitativa do impacto da implantação do processo judicial eletrônico (PJe) na produtividade dos tribunais. Rio de Janeiro, FGV, 2018, <https://hdl.handle.net/10438/22051>. Acesso em: 12 dez. 2020. p. 12.

JUNIOR, Raimundo Pereira da Silva; COSTA, Vicente; SILVA, Maria Valesca Damásio de C. Os Tribunais de Contas Como Instrumentos de Accountability: Impacto da Rejeição de Contas nas <http://conferencias.unb.br/index.php/ccgunb/ccgunb3/paper/download/6021/1592>. Acesso em: 13 nov. 2020.

LIMA, Luiz Henrique. Controle Externo: Teoria e Jurisprudência para os Tribunais de Contas. Rio de Janeiro: Forense; São Paulo: Método, 2015.

OLIVEIRA, Júlio Marcelo de. A Reforma dos Tribunais de Contas Existem dois consensos: a forma de composição majoritariamente política e a total falta de fiscalização. In: FENASTC. Controle Externo Brasileiro em revista. <http://www.fenastc.org.br/wp-content/uploads/2019/02/Edicao 2017.pdf $>$. Acesso em: 12 dez. 2020.

VERNALHA, Fernando Guimarães. O Direito Administrativo do Medo: a crise da ineficiência pelo controle. 2016. < http://www.direitodoestado.com.br/colunistas/fernandovernalha-guimaraes/o-direito-administrativo-do-medo-a-crise-da-ineficiencia-pelo-controle>. Acesso em 20 de dez de 2020. 
VIEIRA, Luciano. Escolha de Conselheiro de Tribunais de Contas: uma questão de moral (e Cívica). Estadão, São Paulo, 18/11/2013. $<$ http://politica.estadao.com.br/blogs/fausto-macedo/artigo-escolha-de-conselheiro-detribunais-de-contas-umaquestao-de-moral-e-civica/>. Acesso em 20 dez. de 2020.

WILLEMAN, Marianna Montebello. Accountability democrática e o desenho institucional dos Tribunais de Contas no Brasil. Belo Horizonte: Fórum, 2020, 2ª ed. 2017. 